\title{
Animator's Roles in Enriching the Content of Tourist Stay
}

\author{
Zlatko Jakovlev, Cane Koteski, Snezana Bardarova, Aleksandra Zezova \\ University Goce Delcev, Stip, Republic of Macedonia \\ Kristijan Dzambazoski \\ Agency for Tourism Promotion of Republic of Macedonia, Skopje, Republic of Macedonia \\ Gorancho Koteski \\ Army of Republic of Macedonia, Skopje, Republic of Macedonia
}

\begin{abstract}
For successful animation of visitors, animators must perform very complex, demanding, and dynamic tasks. Professional performance of tasks implies the need for an animator to be a complete person. This means that he/she not only must have a sound education, but also have to be specialized for certain activities. There are different types of animators so that their diversity mirrors the success of the hotel. Animators must have certain basic physical and psychological characteristics. So, despite the knowledge and experience, animators must have inherent characteristics such as talent, humour, to be friendliness, and so on. Sense of humour and ability to work with people are two important characteristics of a successful animator. Many hotels need animators who can entertain tourists and make their stay memorable resort experience, which will be a reason for return of tourists. One of the key factors for tourism success is animator. Today, the whole tourism sector is based on animation of the tourists. The purpose of this paper is to show the role of the animator in enriching the content of tourist stay. To successfully execute the animation to the tourists, animators must meet certain characteristics which will be analysed in this paper. In this research will be used methods of analysis of scientific literature on the impact of animation on enrichment of tourist stay. The research stems from the fact that animation is one of the most important animation-motivational factors for the development of tourism.
\end{abstract}

Keywords: animator, tourism, recreation, characteristics, tourists, hotels

\section{Introduction}

Animator is a tourist worker, who with his/her general characteristics must meet all required criteria and roles. His/her activity begins with the first contact with visitors, lasts throughout the tourist stay until their departure, which includes sending and promise that the next meeting will strive to meet all of their interests, preferences, and desires. Because of that, he/she is required to have a specific character trait and physical endurance. So, animators have to fulfil certain roles which might render them to be complete people and to have everything that is in the function of enriching the content of tourist stay.

Zlatko Jakovlev, Ph.D., associate professor, Faculty of Tourism and Business Logistics, University Goce Delcev. Email: zlatko.jakovlev@ugd.edu.mk.

Cane Koteski, Ph.D., assistant professor, Faculty of Tourism and Business Logistics, University Goce Delcev.

Snezana Bardarova, MSc., teaching assistant, Faculty of Tourism and Business Logistics, University Goce Delcev.

Aleksandra Zezova, Ph.D., assistant professor, Faculty of Tourism and Business Logistics, University Goce Delcev.

Kristijan Dzambazoski, MSc., director, Agency for Tourism Promotion of Republic of Macedonia.

Gorancho Koteski, Lieutenent-General, Chief of the General Staff, Army of Republic of Macedonia. 


\section{Psychophysical Characteristics of the Animator}

Animators must be psychologically and physically healthy, which means that there must be a person without any mental and physical disabilities. By their external physical appearance, it must be at a higher level, i.e., they must meet stringent criteria. His/her appearance may be one of the important criteria in terms of its final choice. $\mathrm{He} /$ she performs highly complex, diverse, and subtle tasks. For this purpose, the psychological and physical characteristics should be taken into account for selection of animators. In that connotation, according to Butler (1968), the most significant psychological and physical features of the animator include:

(1) Personal and professional honesty;

(2) Sense of humour;

(3) Sense of providing services;

(4) Understanding of animating as art;

(5) Intelligence and common sense;

(6) Good psychophysical health;

(7) Energy and enthusiasm;

(8) The ability for the organization.

Cerovic (1999) also highlighted a number of such features:

(1) Pleasing appearance: Because an animator's activity is related to the subjective judgment of the members of the group, his/her outward appearance should be adapted to the group;

(2) Optimal age of life: Age of animators is specifically determined and should be in accordance with the requirements of the group. They are supposed to be relatively young and experienced;

(3) A stand: Given that animating is a dynamic profession, permanent change will not affect the proper situations and quick decision-making when there is a conflict in communication with the group;

(4) Interest and engagement: Animators should be flexible, because they are changed according to the mood and attitude of the group, and they should be interested to be involved in adapting to the group;

(5) Honesty: With their interpersonal communication with the group, they should possess a high degree of honesty and never have to compromise the trust that has earned the group their verbal or non-verbal actions;

(6) Professionalism: In relation to members of the group, an animator should manifest a high level of expertise and knowledge. This is the only way for an animator to gain great authority;

(7) Natural talent: Given the fact that animation is a complex and specific activity, here creativity comes to the fore. Primarily through interpersonal communication, animators have to spread a feeling of serenity, mood, and balanced humour;

(8) Attention: Because animators work with a group that is heterogeneous, they should leave tourists with the impression that they may not be highly prestigious and have personal ambitions, but for each member of the group, they should be especially careful, ready to help the tourists to solve their dilemma and fear at any time, and satisfy tourists' desires;

(9) Inclination towards art: Animators should have a developed aesthetic sense of beauty and the appropriate and adequate way to convey it to the visitors;

(10) Confidentiality: Animators must have faith in people and start from the assumption that all people have the goodwill and positive intentions. In no case should animators show that they question the human values;

(11) A positive direction: He/she should be a person who is oriented for the good of the group members and cares to achieve their personal positive experiences; 
(12) Intelligence: It will help to make it easier and faster for animators to communicate with the group. With this characteristic, animators can be worn successfully in all conflict situations, be rational in decision-making, realistic, and always cheerful;

(13) Good psychophysical health: Animators should be psychologically and physically healthy, because animation is a laborious and responsible activity;

(14) Vigour and enthusiasm: In the environment, by their actions, verbal and non-verbal contacts must act forcefully, confidently, and with a high degree of enthusiasm and desire to achieve success.

These characteristics lead to the conclusion that the animator is required to have a wider ange of psychological and psychophysical features and a developed sense of hearing, sight, and smell. Here should be added psychomotor properties, i.e., art movement (coordination and grace), rapid response, running, which must be high, coming to the conclusion that his/her health must not be violated. All these psychophysical characteristics should be targeted to meet the needs of visitors, because the animator must create a warm atmosphere filled with "serenity and mood" (Moisset, 1996).

Due to the abovementioned, the following important aspects of the scope of communicability are required of animators:

(1) Clear verbal expression, which means that animator should have a solid excuse with a clear and correct emphasis. Those who have certain disadvantages in terms of speech expression or some hearing damage have no way to deal with this profession;

(2) Emotional resilience, which involves a high degree of self-control that animators should manifest in a number of different conflict situations;

(3) Tact, a feature that animators are supposed to possess, especially to those visitors in the group requiring a special attention, and they should be more careful to them;

(4) Ability to remember the means of observing not only the major events, but also the small details which will be of great benefit for the animation process;

(5) Ability to communicate skillfully, which is believed by many to be the primary means of animators. The success of the animation depends on the communicability which reflects certain skills, habits, knowledge, personality traits, and other psychological and physical characteristics. In this context, the animator must constantly be improved, because communication is the result of all the knowledge, skills, and capabilities which he/she owns and which are manifested through the clear speech ability, appearance, and other forms of communication (Cerovic, 1999).

In fact, it comes to verbal communication, which is very important, because an animator is in constant and direct contact with visitors. That is verbal communication which is very important for the animator, because he/she is in constant and direct contact with the visitors. The purpose of verbal communication is to act, assure, and recruit, which is especially important in animation, because as previously pointed out, interpersonal communication is the essence of animation. Animators must pay great attention to the verbal expression, which is achieved by constant practices. Except for the way of excuse, he/she should raise his/her skill for speaking. Animators need to recognize and respect different cultures and areas from which visitors come, meaning that this form of communication should be improved to the highest level of professionalism. In this context, it may be pointed out that Cicero as a result of perseverance and plenty of exercise, by a man with a speech impediment, became a backbone. 
Animator is necessary to perfect and non-verbal communication. For successful realization of the animation programs, animators use non-verbal cues such as body movement, tone, mimics, gestures, and facial expressions that include smile. In this connotation, a prominent hotelier said, "For good operation of the hotel, it is important to determine the location, but for the warm atmosphere in the hotel, it is important to smile" (Štimac, 1975). The animator's style of dressing and his/her outward appearance play important roles in non-verbal communication, i.e., face, hair, hands, and more.

\section{Roles That an Animator Should Meet in Relation With the Visitors}

Besides the psychological and physical characteristics for a successful implementation of animation programs, animators must possess expert knowledge and everything for successful accession of the individual and the group as a whole. Namely, in a new and unfamiliar environment, some visitors are often badly adaptable. In order to address these situations in tourism, the animator has the most important role. To meet the complex requirements that are required of the animator, he/she should have emotionally and socially constructed personality, positive character traits, and be professionally trained to deliver programs of animation. In this context, Kripendorf (1986) considered that animation should be run by educated animators with special personal characteristics and with the best pedagogical education. Such animation today is still rare, but is often misinterpreted and commercialized. An animator, to successfully organize and realize the animation programs, must meet certain roles in terms of visitors, because he/she knows the various aspects of the tourism offer.

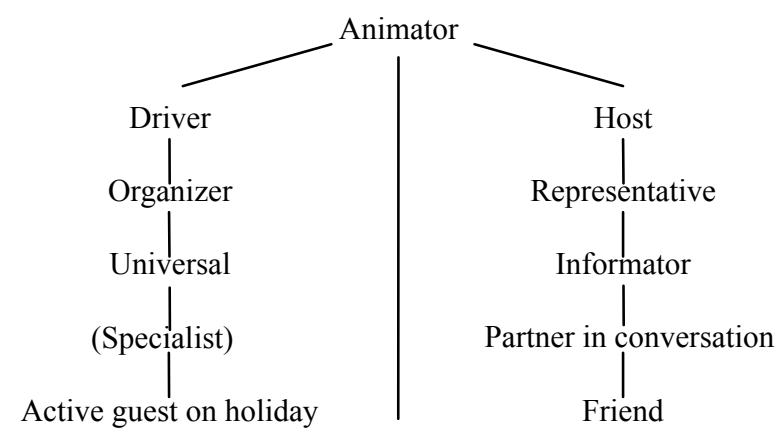

Figure 1. Schematic representation of the roles of animators. Source: Finger and Benoit (1988).

The basic features of the roles set out in the scheme under Cerovic (1999) are:

(1) Colleague: Animator to visitors should be set as a colleague, but not in the professional sense, because they will be participating in the same activities during the tourist stay. We can say that success is the animator who to the guests will be set as a colleague and assist in animation programs;

(2) Driver: Group, animators, and spiritual adviser of their activities. This role is particularly significant for those visitors who are more difficult to adapt to the new environment. Animators perform with all their knowledge, skills, dexterity, and creativity and motivate guests to stay active;

(3) Organizer: In order to successfully realize animation programs, animators need to be successful organizers, because visitors see it as colleague, counsellor, and above all personality which they can rely;

(4) Universal: Animators not only need to know all the contents of the animation, but should also have a wider education and general culture. It actually means that he/she will be able to handle in any situation including even extreme cases; 
(5) Specialist: Despite its universality, he/she should be a narrow specialist for a specific animation activity;

(6) Active guest on holiday: First of all, an animator is a tourist worker who encourages and organizes animation activities. He/she should be an active member of the group. If an animator behaves as an active guest on holiday, each member of the group will perceive him/her as their colleague;

(7) Host: Animator is a representative of the hotel, the place, and the country as a whole. In every situation, he/she should make it clear that he/she was proud to belong to the community that he/she represents;

(8) Representative: This role of the animator does not give him/her any special power, but means that it protects the interests of the hotel, resort, and even the country as a whole;

(9) Informator: Animator is the carrier of information to visitors. Guests as a group or individual are usually interested about their stay in the country, population, its culture, and customs. For this reason, animators need to have a wide range of knowledge and information and should timely inform the subjects who show an interest in some information about the foreign country;

(10) Partner in conversation: It is known that interpersonal communication is the essence of animation. It is actually a conversation between two or more persons. Through dialogue, visitors get various information in their domain of interest and ask a number of questions in the process of animation. Through conversation, animators will instruct guests in the direction that better exploits the benefits which allow tourist destination;

(11) Friend: If you establish a professional, but at the same time, friendly relationship between animators and members of the group, the success of the animation is inevitable. But here, it should be noted that friendship should in no case exceed the normal limits that would distort their roles and place in animating.

\section{Professional Profile of Animator}

Starting from the fact that the animation is a very complex activity, it logically raises the question of the need for a sound general and specialized education for all segments of the animation. Unfortunately, in these current conditions, a structured education of staff in this profile still lacks in our country. The entities that are interested in this issue, i.e., who want to deal with this phenomenon, should have a broad knowledge of all aspects of animation. Namely, from our point of view, animators should have a university degree in the field of tourism or related areas. In addition, they need to pass an exam for animators, which would consist of a theoretical and a practical part and it would be realized: Faculty of Tourism and Hospitality in Ohrid at University "St. Kliment Ohridski", Bitola; Faculty of Tourism and Business Logistics in Gevgelija at University "Goce Delcev", Stip; Faculty of Natural Sciences and Mathematics in Skopje at University "St. Kiril i Metodij"; and the Private University of Tourism and Management in Skopje. We believe that their scientific and professional staff, through a specially designed curriculum, will satisfy the requirements imposed by modern trends in tourism for education of the professional animators. For successful monitoring of the modern tourist flows, animators should permanently improve themselves through participation in various courses, seminars, and through their personal involvement by using additional literature, such as various textbooks, encyclopaedias, manuals, and more.

In this context, according to Relac and Bartoluci (1987), the following are considered as appropriate experts for sport-recreational animation:

(1) Technicians' sports recreation;

(2) Coaches' separate activity;

(3) Senior organizers for recreation;

(4) Professors of physical education, recreation trained. 
As most appropriate experts for cultural-entertaining animation, Buntasheski (2001) proposed: university art historians, ethnologist graduates, musicologist graduates or music teachers, and graduates in tourism and hospitality. According to Buntasheski (2001), animation outings and visits could engage the following profiles: graduate in tourism and hospitality managers, graduate art historians, ethnologist graduates, professors of geography, and the like.

For successful programming and implementation of the contents of the animation, an animator has to be a complete person. It specifically means that he/she should have a broad general and tourist culture. Animators must have an extensive knowledge of the socio-economic system of the Republic of Macedonia and the history of the Macedonian people, given the fact that visitors will be interested in our country, its social, political, and economic regulation, as well as our national history. Shouldn't there be improvisation on this field? Given the fact that the animation in tourism activity is concerned with animators whose aim is to enrich the tourist guests, it can be noted that there is a direct communication between animators and visitors. For this purpose, it requires knowledge of tourism as a socio-economic phenomenon. In this context, it should be equipped with knowledge and information on the changes of tourist facilities in our country and elsewhere. An animator should also possess a great knowledge of the cultural and historical monuments and cultural institutions in our country. Information that are given to the visitors are part of the own tourist culture of the animator. The process of giving the information is a complex socio-psychological interpersonal relation between animators and visitors. For that reason, animators need to have a basic knowledge of communicative activities. Animators should have a basic knowledge in the field of psychology, especially the psychology of tourism and hospitality. This is necessary, because animators met different types of visitors who have different properties and exhibit different reactions. Professional profile of animators would not be complete without the knowledge of foreign languages. Namely, every tourist-catering worker should have knowledge of foreign languages, and in particular, it relates with animator (minimum two worlds). It stems from the fact that animator communicates with heterogeneous tourist table which has a variety of linguistic, cultural, religious, and national characteristics. Besides, animators should have specific specialist knowledge. In this connotation, he/she should have knowledge of his/her expert and psychological profile, know all aspects of animation in tourism, and possess great knowledge about visual communication at animation in tourism. Besides the above theoretical findings, according to Cerovic (1999), an animator has to be someone who has some experience, i.e., practical need to have knowledge of the following:

(1) Work with microphone;

(2) Practical exercises in visual communication workshops;

(3) Specialized workshops for creating objects in the domain of animation;

(4) Conducting games;

(5) Practically carrying hobbies and the like.

\section{Concluding Remarks}

It can be concluded that the animation should be a necessary part of the Macedonian tourist offer, because it is the only way their goals may be reached. In this way, visitors will know the culture of our country in the widest sense. Given that this notion is incorrectly realized, animation sometimes comes down to pure fun which can lead anyone who has little talent. This way will degrade the function of animation as a cultural activity as well as the function as a tourist animator worker. In order to address such adverse conditions, it is necessary to properly understand the concept of animation, especially animators. Therefore, the animation must be run by professional animators. 
To successfully animate visitors, animators have to perform very complex, demanding, and dynamic tasks. Professional performance of tasks implies the need for an animator to be a complete person. This means that he/she not only must have a sound basic education, but also have to be specialized for certain activities. Also, he/she should have a sense of identifying the needs and preferences of visitors as well as organizing the group. Animators need to have such a relationship with the members of the group in which they would perceive an animator as an active member of the group. Thus, a psychological atmosphere needs to be created. In this way, their mental, general, and special abilities are especially prominent. Also, an animator should be a dynamic, initiative, and emotionally and socially mature person with a highly developed sense of humanity and responsibility. For animation to be successful, it should be carried out by all members of the hotel, i.e., teamwork is necessary, and the animator is an equal member of the business team. Also, it is necessary to emphasize that the animation cannot and should not serve to cover up the shortcomings in terms of quality of service, because then it ceases to be animation.

\section{References}

Buntasheski, B. (2001). Animation in tourism offer. Ohrid: Research Institute of Tourism.

Butler, G. D. (1968). Introduction to community recreation. New York, N.Y.: McGraw Hill Inc..

Cerovic, Z. (1999). Characteristics of animators in tourism animation in hotel tourism offer. Opatija: Croatian Association of Hoteliers and Restaurateurs.

Finger, C., \& Benoit. (1988). Lectures on training animators. Rabac.

Kripendorf, J. (1986). Traveling humanity. Zagreb: SNL and the Institute for Tourism Research.

Moisset, P. (1996). Accueil et animation. AFIT Agence Francaise de I'ingenierie touristique, Oktobar, Tournai, Belgique.

Relac, M., \& Bartoluci, M. (1987). Tourism and sport recreation. Zagreb: Informator.

Štimac, K. (1975). The influence of the successful reception room guest in the hotel. Bulletin 3, Zagreb. 